\title{
Assessing the Use of Virtual Reality Technology in Teaching Marine Ecological Concepts
}

\author{
Emily Duwan', Francis Choi', and Brian Helmuth
}

\author{
${ }^{1}$ Marine Science Center, Northeastern University, Nahant, MA \\ Keywords: Environmental Education, Experiential Learning, Intertidal Ecology, Interactive Learning Environments, Virtual Reality \\ Publication Date: August 19, 2019 \\ DOI: https://doi.org/10.15695/jstem/v2i1.14
}

\begin{abstract}
Virtual reality environments are becoming increasingly popular as educational tools, but it remains unclear when these environments enhance learning or when they are a distraction from the learning process. We compared two different methods for teaching ecological concepts about the rocky intertidal zone by comparing an experimental (virtual) class with a control (traditional) type of class. We investigated whether cognitive (i.e., knowledge) and affective (i.e., attitudes, perceptions) outcomes are enhanced when students use lesson plans presented in a virtual reality environment compared with lesson plans facilitated via traditional methods. We also assessed the extent to which these attributes are enhanced when students create their own virtual tours as part of a field-based learning experience. The experimental group showed significantly higher maintenance of knowledge gain than the traditional group at the conclusion of the study, but there were no other significant differences among treatment groups. Feedback from teachers reported that students were more engaged, had better recall, and enjoyed the change from the traditional lecture style. Lack of statistically different scores measuring excitement suggests a need for improvement in the design and implementation of these virtual environments to maximize their appeal to students. However, our results suggest that virtual reality technologies provide an innovative alternative to standard lesson plans that can help improve knowledge retention about ecological concepts.
\end{abstract}

\section{INTRODUCTION}

Climate change and other stressors impacting the marine environment have made teaching ecological concepts increasingly important (Wrzesien et al., 2010). Recent pedagogical and technological advances have enhanced student learning about different aspects of marine ecology but there is still difficulty in motivating students in traditional classroom settings (Wrzesien and Raya, 2010). While experiential, hands-on learning continues to gain prominence (Sianez et al., 2010), taking students on field trips is often expensive and logistically difficult, especially when studying coastal environments and can especially be a challenge for students with disabilities (Gilley et al., 2015). Educators are taking advantage of appealing aspects of technological solutions to student engagement (Nincarean et al., 2013), and there has been an increased use of computers and mobile platforms such as tablets and smart phones as educational media to stimulate interest and learning both inside and outside of the classroom (Moren-Ger et al., 2008). There is also an increasing emphasis on making learning more personalized, and new teaching methods are focused on making the student the center of the learning process (Boada et al., 2015). In order to accomplish these goals, there is a growing use of simulations, including serious games (Guillen-Nieto and Aleson-Carbonell, 2011) and virtual reality (VR) environments (Yahaya, 2006), in both formal and informal educational institutions.

Simulations that represent real-life contexts have been shown to enhance deeper conceptual thinking in students (De Freitas and Neumann, 2009). Less is known about the application of virtual reality technology used in conjunction with experiential learning, and specifically whether handson learning experiences can be enhanced using simulation tools. Moreover, understanding student motivation is one of the most difficult aspects of teaching. Since students do not explore and observe environments the same way in traditional classrooms as they do in virtual reality environments (Wrzesien et al., 2010), it is unclear whether the use of VR can enhance learning, or if it is instead a distraction to students, potentially reducing learning effectiveness (Wrzesien and Raya, 2010).

Virtual reality (VR) environments can be defined as interactive, multi-sensory, three-dimensional, computer synthesized environments (Tsiastos et al., 2010). VR environments that provide enhanced visualizations (De Freitas and Oliver, 


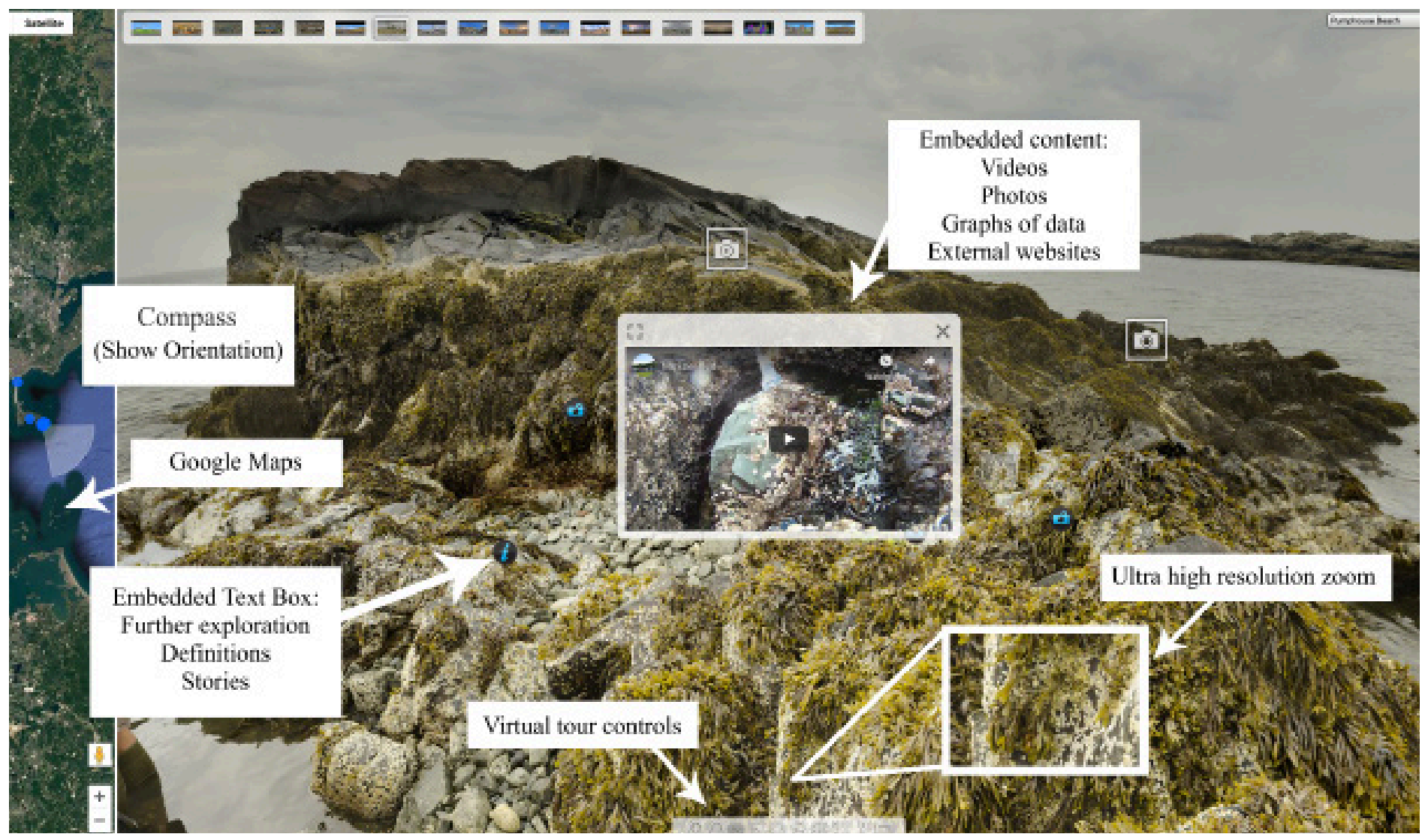

Figure 1. Screen shot of GigaPan $\left(360^{\circ}\right.$ virtual tour) displaying assets that can be embedded into the tour. These tours can be accessed from any computer, mobile device or VR headset.

2006) and interactive learning environments have been increasingly developed in recent years (Tsiastos et al., 2010). VR technology provides a new way of approaching learning through exploration while students engage with multiple forms of media (De Freitas and Neumann, 2009). Serious virtual worlds (SVWs), or 3D environments with learning objectives, are recognized to have considerable potential in education (Wrzesien and Raya, 2010). SVWs are an alternative to current teaching methods where students are passive learners, most often listening to a lecture delivered by their teacher. The goals of these SVWs are to make learning content effective and engaging, and to capture students' attention when learning various scientific concepts (Wrzesien and Raya, 2010).

Learning through exploration (exploratory learning) is thought to be a strength of VR learning, allowing players to move freely through an environment at their own pace (De Freitas, 2006). For example, Wrzesien and Raya (2010) created a virtual aquatic world through which students navigated to learn about the Mediterranean Sea. Many studies have shown that computer simulations can serve as an effective means of motivating and engaging students with different learning styles and to support learners who are more visually orientated (Moreno-Ger et al., 2008). Bhagat et al. (2016) for example, showed better learning motivation, learning out- come, and positive impact on scores through the use of VR technology when compared to traditional methods. However, other studies have found that the attractiveness of the VR technology can sometimes be a distraction for students and may reduce learning effectiveness (Papasterigou, 2009).

This study explores whether VR environments can serve as an effective tool for teaching ecological concepts as part of a field trip experience, and tests the extent to which it may increase student knowledge gain and excitement about science (Wrzesien et al., 2010). This study also explores the use of VR technology as a means of "flip learning" (Liou et al., 2016), which further distances students from their more traditionally passive role in the classroom (Hussain et al., 2015). In a flipped classroom --popularized in part because of greater availability of technology-- students learn concepts using online resources, including videos, outside of the classroom. This allows students to explore topics on their own, at their own pace, and moves from a group learning space to an individual learning space (Liou et al., 2016). This reverses the traditional learning environment where instructional content is delivered inside the classroom, and is only reinforced outside of the classroom using, e.g., homework assignments (Liou et al., 2016). For example, students can watch pre-recorded lectures at home as homework in advance of class which allows for more time for discussion 


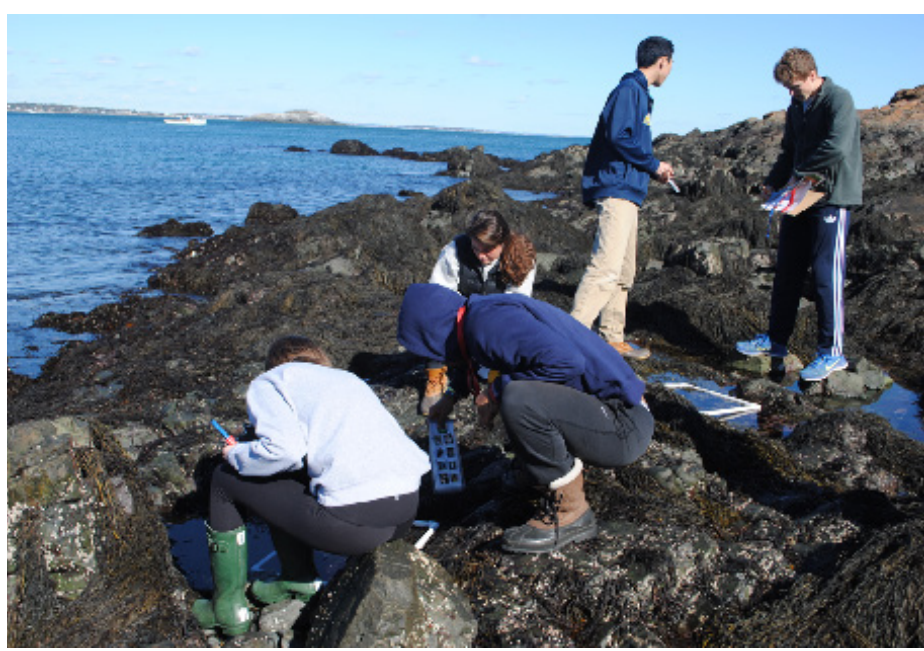

Figure 2. Field site located in Nahant, MA. This is one of the sites where students conducted their rocky shore survey. Students pictured are taking measurements in the low region of the rocky intertidal zone.

of material or time to work on projects during class (Hussain et al., 2013). Flipped learning may occur in a more experimental and less structured way than more traditional methods of learning where it is hard to entice children (De Freitas and Neumann, 2009). Positive impacts of flipped classrooms show greater engagement and improved learning performance (Liou et al., 2016). VR environments can be accessed via a computer so students are able to use this technology at home as part of a flipped classroom program which leaves more time for discussion in class. An additional goal of this study is therefore to study the efficacy of a VR technology, GigaPan, as a tool for flipped learning.

Finally, we assessed the extent to which excitement and knowledge gain and retention are enhanced when students co-created (with investigators) their own virtual tours appended with stories, photos, and data that they collected during a field trip. This technology is not meant to replace in-field learning but rather enhance students' experiences before and after field trips.

\section{METHODS}

We used rocky intertidal habitats as a model system. Because of steep clines in environmental conditions moving from low shore to high shore, rocky intertidal habitats have long served as a model system for examining the relationships between organisms and their physical environment (Paine, 1994) and more recently have emerged as an ideal habitat in which to study climate change impacts (Thorner et al., 2014). These habitats have the advantage of being reasonably accessible to students in coastal communities, but with the obvious caveat that they are inaccessible to students from anywhere but schools near the ocean. Our primary goal was thus to assess not only whether the use of VR technology enhanced learning by students able to access coastal sites, but also to determine if VR could offer meaningful experiences to students for whom access was logistically impractical.

The tool used for this study focuses on the use of GigaPans, which are 360-degree high-resolution images each stitched together from $\sim 300-400$ high resolution (14 Megapixel) images taken using a standard DSL camera on a motorized mount. The Gigapan image functions as a "palette" that can be annotated with images, PDFs, URLs, and videos that are "pinned" anywhere on the image (Figure 1). The final product, a "virtual tour", can be accessible by computer, mobile device or VR headset.

To evaluate if basic understanding of the ecological principles operating in intertidal ecosystems is enhanced with the use of the GigaPan technology, surveys were used to assess knowledge, attitudes, and depth of understanding before and after students used this technology. We used a control group of students taught using lectures to compare the GigaPan technology to more traditional classroom methods. In order to foster improvements in future designs of SVWs to increase learning effectiveness and appeal we also obtained feedback from participating teachers through an open-ended survey. We hypothesized that students with the ability to explore virtually will have an enhanced sense of understanding of the rocky intertidal ecosystem, and will be more excited about participation in hands-on exercises. We also hypothesized that there would be significant improvements to students' learning and excitement when they create their own virtual tours, with the assistance of the investigators.

Research Design. This study compared two different learning methods: a traditional method (control group; $n=53$ students), and an experimental method using GigaPan virtual reality ( $\mathrm{n}=58$ students), and took place between September-November, 2016. The content and learning objectives of an introduction to the rocky shore environment were the same for each of the two treatment groups. For the first part of the study, the control group was presented with traditional teaching methods, which included a lecture with slides that lasted approximately 20 minutes. The experimental group had a similar curriculum embedded into an online VR environment through the use of a GigaPan virtual tour. Participants in this experimental group were able to virtually explore a rocky intertidal field site located in Nahant, MA. This introduced them to a rocky shore site similar to one where they (and the control group) would later conduct field surveys. Students in the experimental group explored different zones in the intertidal ecosystem in high resolution via a VR tour populated with instructional videos and slides describing the rocky intertidal habitat (http://www.northeastern. edu/helmuthlab/eastpoint.html). Both groups then conducted a series of exercises at a rocky intertidal field site over the 
Table 1. Likert scale questions from surveys where participants indicated their agreement with different statements.

\begin{tabular}{lcccc} 
Statement & Not at All & A Little & Quite a Bit & Yes, Definitely \\
\hline I feel confident in my ability to do science. & 1 & 2 & 3 & 4 \\
I am interested in a science job when I am older. & 1 & 2 & 3 & 4 \\
This program made science seem more interesting to me. & 1 & 2 & 3 & 4 \\
I feel prepared for our field trip. & 1 & 2 & 3 & 4 \\
I would like to learn more about the rocky shore. & 1 & 2 & 3 & 4 \\
I would like to go on more field trips to study the marine environment. & 1 & 2 & 3 & 4 \\
This program improved my understanding of science. & 1 & 2 & 3 & 4 \\
I am excited about science. & 1 & 2 & 3 & 4 \\
Science seems fun. & 1 & 2 & 3 & 4 \\
\end{tabular}

course of a single low tide ( $\sim 3$ hours). During this survey in the field, students in both experimental and control groups collected data and used scientific tools to measure abiotic (salinity, temperature, dissolved oxygen) and biotic factors (species distributions, biodiversity) in the intertidal zone. They also took photos and videos with cameras provided to them. In order to test if there was a further enhancement of learning and excitement using VR, the experimental group then made their own GigaPan VR tour with the data, photos and videos that they collected. The control group made a poster using information that they collected at the same field site.

Study Participants. A total of 111 students (50 females, 61 males) who were enrolled in marine science classes participated in this study. The age of the participants ranged from 15-19 years old and all participants were students in the 10th-12th grade at a high school in the Commonwealth of Massachusetts. Parents of all participants signed informed consent forms and researchers obtained informed assent from each student at the beginning of the study. Participants had the opportunity to ask questions before the start of the study and were instructed that all answers were voluntary and there would be no penalty for not answering a question, or for answering incorrectly.

Description of Classes and Learning Goals. The research team developed each class for the two different methods of teaching about the rocky intertidal ecosystem. The subject matter was the same for both types of classes. Intertidal ecosystems comprise the area of the shore that is between high tide and low tide along the world's coastlines. There are numerous ecological factors that affect animals and plants (seaweeds) inhabiting this zone and given the small scales over which these factors change, intertidal systems have long been models for ecological research (Paine, 1994). In general, intertidal invertebrates and seaweeds are evolutionarily of marine origin but must contend with exposure to air during daily low tides. As a result, a regular feature of most intertidal ecosystems is the presence of "zonation", a series of abrupt bands where one species replaces another, presumably as a result of environmental conditions which become increasingly harsh moving from the lower to upper intertidal zones. The concepts covered for both the experimental and control groups included introductory information on the rocky shore ecosystem: how organisms interact with their environment, differences among tidal zones and zonation patterns, taxonomic classification of marine organisms, ecological factors that affect the intertidal zone and marine organisms' adaptations, tools needed to measure abiotic stressors (temperature, dissolved oxygen and salinity) that affect intertidal organisms; concepts of biodiversity; differences in the physical environment between the low and high shore; and an explanation of techniques and equipment that would be used during the field trip to this environment.

For the experimental group, these concepts were presented as embedded videos, photos and sample data in the virtual tour; for the control group, this information was presented in a classroom setting using a traditional PowerPoint lecture presentation. Participants in the experimental group were instructed to navigate through the GigaPan on a desktop computer where they would click on lecture slides embedded in the virtual world. This included three different GigaPans corresponding to different zones in the intertidal ecosystem (upper, middle and lower). A series of videos (created by the research team) describing biodiversity, temperature, salinity, dissolved oxygen and tides were also embedded in the online virtual tour.

The purpose of both of these lesson plans was to prepare students for a field survey conducted at a rocky intertidal field site. Students came to the Marine Science Center in Nahant, MA or a field site located close to their school for the field trip (Figures 2, 3). In these field surveys students measured and compared patterns of biodiversity, temperature, dissolved oxygen, and salinity in upper, middle and lower 
Table 2. Summary of results for Likert scale questions on science interest and excitement. Statements were compared using Mann-Whitney $U$ tests for differences between the two treatment groups.

\begin{tabular}{|c|c|c|}
\hline to & W-value & p-value \\
\hline I enjoy playing video games & 1574 & $>0.05$ \\
\hline I am excited to be in this class & 1414 & $>0.05$ \\
\hline I am excited about science & 1535 & $>0.05$ \\
\hline $\begin{array}{l}\text { I am interested in a science job when I } \\
\text { am older }\end{array}$ & 1669 & $>0.05$ \\
\hline Science seems fun & 1606 & $>0.05$ \\
\hline I am confident in my ability to do science & 1472 & $>0.05$ \\
\hline $\mathbf{t}_{\mathbf{1}}$ & W-value & p-value \\
\hline $\begin{array}{l}\text { I get excited to find out that I will be } \\
\text { doing a science activity }\end{array}$ & 1552 & $>0.05$ \\
\hline $\begin{array}{l}\text { I am confident in my ability to use scien- } \\
\text { tific, computers, or technology }\end{array}$ & 1532 & $>0.05$ \\
\hline I learned a lot about the rocky shore & 1588 & $>0.05$ \\
\hline I enjoyed the rocky beach lesson plan & 1814 & $<0.05^{*}$ \\
\hline $\begin{array}{l}\text { I would like to learn more about the } \\
\text { rocky shore }\end{array}$ & 1587 & $>0.05$ \\
\hline I am excited for our class project & 1370 & $>0.05$ \\
\hline I feel prepared for our field trip & 1359 & $>0.05$ \\
\hline $\mathbf{t}_{2}$ & W-value & p-value \\
\hline I enjoyed my experience out in the field & 1558 & $>0.05$ \\
\hline $\begin{array}{l}\text { This program made science seem more } \\
\text { interesting to me }\end{array}$ & 1479 & $>0.05$ \\
\hline $\begin{array}{l}\text { This program made me feel more relaxed } \\
\text { about learning science }\end{array}$ & 1562 & $>0.05$ \\
\hline $\begin{array}{l}\text { This program improved my understand- } \\
\text { ing of science }\end{array}$ & 1282 & $>0.05$ \\
\hline Technology is important for science & 1496 & $>0.05$ \\
\hline $\begin{array}{l}\text { I would like to go on more field trips to } \\
\text { study the marine environment }\end{array}$ & 1341 & $>0.05$ \\
\hline
\end{tabular}

*Indicates significant differences.

intertidal zones.

After the field trips, students from the experimental group created PowerPoint slides with their teachers as a post-field trip debrief. Teachers then gave materials (data, photos, videos, etc.) they had created with their students to the research team, which were then used to create a GigaPan virtual tour. The research team created the template for the virtual tour earlier by taking photos with the GigaPan robotic hardware. Teachers provided their students with a print version of the tour and asked to indicate where on the GigaPan they wanted their materials to be presented. The main goal of the tours that they created was to compare tide pools from three elevations (Figure 4). The control group made their own poster with their teacher with the same information collected. Both groups spent the same amount of time with the research group and spent the same amount of class time creating the final products. Before the final post survey students presented their poster or online virtual tour to the rest of the class.

Surveys. To test for differences in attitudes and knowledge gain, a total of three paper-based surveys were conducted at three different times throughout the study. Each participant completed surveys individually in the presence of their teacher and researcher. The first survey was given at the start of the study (to). The second was given after the lesson plan was completed for each group but before the field trip component $\left(t_{1}\right)$ and the third was given at the conclusion of the study $\left(\mathrm{t}_{2}\right)$. At the start of the study ( $\left.\mathrm{t}_{0}\right)$ each student filled out a pre-knowledge and attitudes survey. This survey included anonymous biographical questions, including gender, grade, age, and frequency of participation in various science activities. The next section of the survey was used to assess attitudes in science. Participants were instructed to indicate their agreement with 12 different statements such as: I am excited about science; I am confident in my ability to do science; I am interested in a science job when I am older; etc. A Likert scale was used with the following descriptions: not at all; a little; quite a bit; and yes, definitely (Table 2). The third part of the initial (to) survey was a set of knowledge questions to assess student's background knowledge of scientific concepts relating to the rocky shore before the study began. These knowledge questions were chosen from a set of 30 multiple choice questions developed by the research team from the content presented to each treatment group. Each of the three surveys had 10 knowledge questions that were randomly chosen from the set of 30 questions. Therefore each of the three surveys had a different set of questions but with the same difficulty level. A second version of each survey was also made with a different set of randomized questions. This allowed researchers to assess knowledge gain and maintained the gain throughout different times of the study.

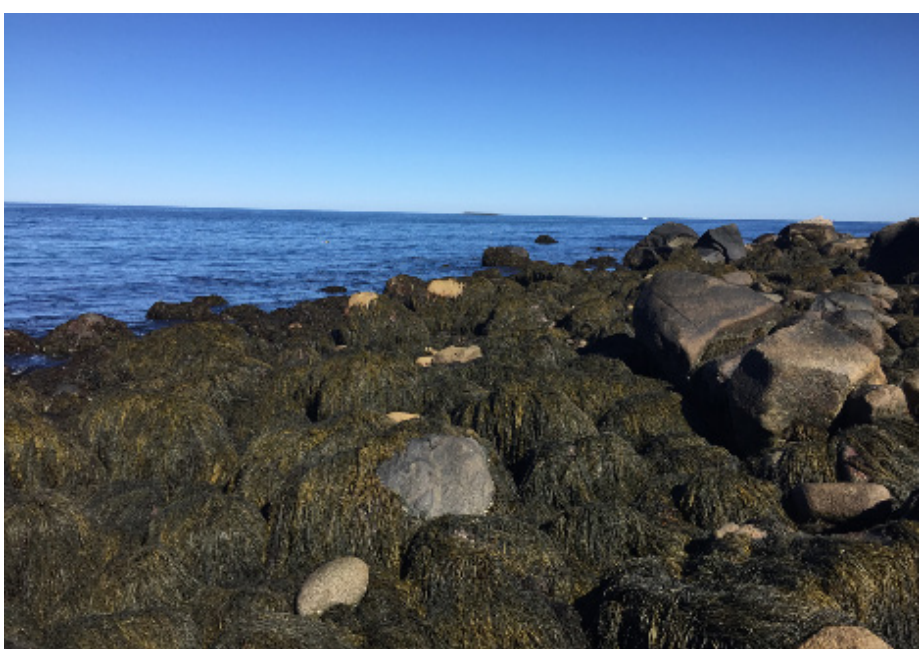

Figure 3. Field site located in Rockport, MA where students from Rockport High School conducted their rocky shore survey. 
Table 3. Summary of results for statements that were used in the before and after comparison for Likert scale questions on science interest and excitement. Statements were compared using a generalized linear model for differences between the two treatment groups.

\begin{tabular}{l}
\hline Statements \\
\hline I am excited about science \\
I am interested in a science job when I am older \\
Science seems fun \\
I feel confident in my ability to do science \\
Scale \\
\hline
\end{tabular}

The second survey $\left(\mathrm{t}_{1}\right)$ was administered immediately following the rocky shore lesson plan. This survey included similar questions and another set of 10 knowledge questions to assess knowledge gain between the two different treatments. The final survey was given at the conclusion of the study $\left(\mathrm{t}_{2}\right)$ after the field trip and after each treatment group had made and presented either their GigaPan (treatment) or poster (control). This survey included a similar set of statement questions as the first survey and another set of 10 knowledge questions. Each treatment group was given the same set of surveys.

Procedure. Different sections of classes were randomly chosen to be in the experimental or control group. All 111 participants filled out the three surveys in the same manner. Each school visit was performed during normal school hours in their respective classrooms. Each survey was kept anonymous and the time needed to fill out each survey was approximately 15-20 minutes. Informal observations relating to student engagement, attention, enjoyment and any other variables considered to be relevant were made throughout the study. Feedback was obtained through an open-ended survey from each teacher to assess student's enjoyment and engagement of different methods of learning.

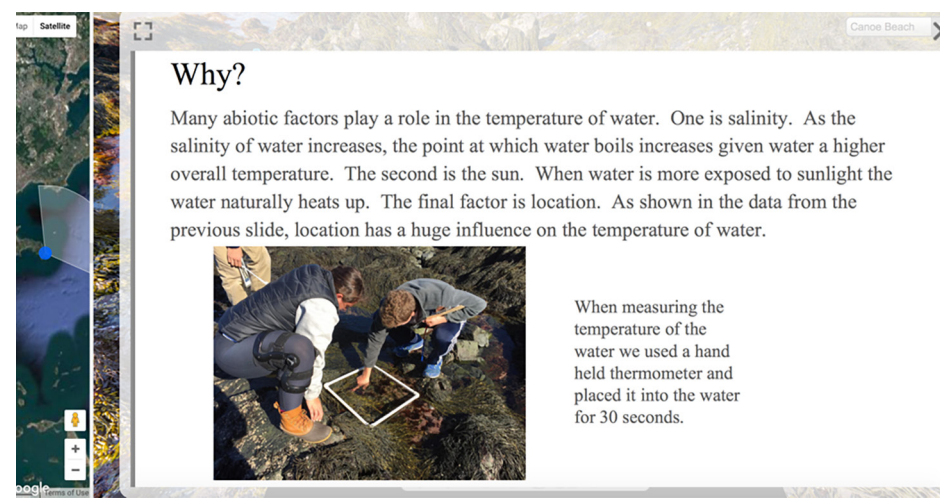

Figure 4. Example of virtual tour created with students populated with data, observations, and pictures collected during their field trip to the Marine Science Center, Nahant, MA.
Data Analysis. Differences between the traditional (control) and experimental group were analyzed using R Studio and SPSS programs. The mean number of science activities participants completed in the last three months was compared between the two treatment groups using a non-parametric t-test (Mann-Whitney U test). Responses to Likert scale questions on science interest and excitement were compared using Mann-Whitney U tests for differences between the two treatment groups. There were four interest and excitement statements (Table 2) that were asked at the beginning of the study and the conclusion of the study $\left(\mathrm{t}_{2}\right)$. These statements were compared using a generalized linear model (GLM) to examine differences between the control and experimental group over time. In each survey the total correct number of knowledge questions was calculated to give a score from 0 -10. A generalized linear model (GLM) was also used to examine differences in knowledge gain between the control and experimental group over time.

\section{RESULTS}

Comparison of Background Variables and Demographic Questions. There was no significant difference between the mean number of science activities completed in the last three months between the two treatment groups (Mann-Whitney $\mathrm{U}$ test, $\mathrm{W}=1678.5, \mathrm{p}>0.05)$. There was also no significant difference in the initial excitement levels between the two treatment groups (Table 3). Overall participants reported that they enjoyed learning outside the classroom (Mean \pm S.D.: $3.12 \pm 0.87$ ) significantly more than inside the classroom $(1.86 \pm 0.76 ; \mathrm{W}=10146, \mathrm{p}<0.05)$. The remaining statements for to were not statistically different between the two treatment groups (Table 3).

Excitement. Participants in the control group (2.85 \pm 0.72$)$ enjoyed the rocky shore lesson plan significantly more than participants in the experimental group $(2.59 \pm 0.70$; $\mathrm{W}=1814$, $\mathrm{p}$-value $<0.05)$. The remaining statements on the $\mathrm{t}_{2}$ survey did not show any statistically significant differences among treatments with regards to excitement level (Table 3). There were no significant differences between the two treatment

Table 4. Summary of results at each time point and interaction

\begin{tabular}{lcc}
\hline Time Points & W-value & p-value \\
\hline $\mathrm{t}_{0}$ & 1331 & $>0.05$ \\
$\mathrm{t}_{1}$ & 1140 & $>0.05$ \\
$\mathrm{t}_{2}$ & 995 & $<0.05^{*}$ \\
Interaction & AIC value & p-value \\
\hline & 1201 & $<0.05^{*}$ \\
\hline
\end{tabular}

* Indicates statistical differences 


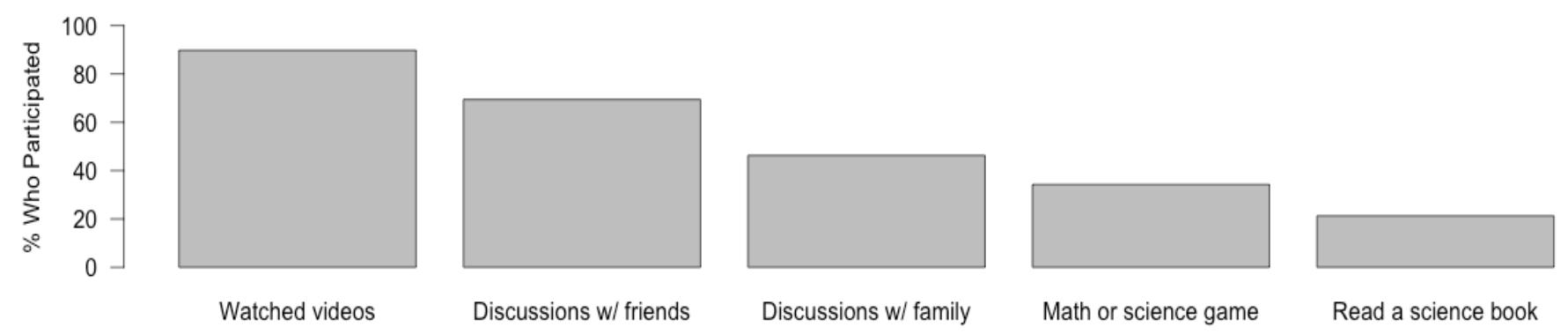

Figure 5. Science activities in which the highest percentage of students participated in during the last 3 months.

groups for the 4 statements for the before and after comparison $(\mathrm{GLM}, \mathrm{df}=1,1, \mathrm{AIV}=471.137, \mathrm{p}>0.05$, Table 4). None of the statements related to excitement at the end of the study ( $\mathrm{t}_{2}$ were statistically different between groups (Table 3).

Knowledge Gain. Both time and treatment group were significant for knowledge gain and there was a significant interaction between the two factors (GLM, df=1,2, $\mathrm{AIC}=1201.005$, $\mathrm{p}<0.05$; Figure 5). There were no significant differences in knowledge gain between the mean scores of the control group (4.92 \pm 1.79$)$ and the experimental group (4.81 \pm 1.46$)$ at to (Table 4). Overall both the experimental and control groups had a significantly higher mean score at $t_{1}$ compared to the start of the study ( $\mathrm{t}$; $\mathrm{W}=8093.5$, $\mathrm{p}$-value $<0.05$ ) but there was no significant difference in knowledge gain between the control group $(6.12 \pm 1.89)$ and the experimental group (6.68 1.48$)$ (Table 4). However, at the end of the study, $\mathrm{t}_{2}$, the experimental group (6.70 1.65$)$ had a significantly higher mean score than the control group ( $\mathrm{M}=5.98$, $\mathrm{SD}=1.53 ; \mathrm{W}=994.5, \mathrm{p}<0.05$, Table 4) indicating a higher retention of knowledge gained.

Observations during Classes and Summary of Feedback from Teachers. Participants in the experimental group were very enthusiastic when first opening the virtual tour and overall engagement was high. There was a high level of attention for the control group at the beginning of their class periods that seemed to lessen during the remainder of the lecture. Some students in the GigaPan (experimental) group seemed to become frustrated if a video wouldn't load quickly (when all students were trying to watch a video at once), especially in schools with slower Internet connections. Students also read at different paces and some moved more quickly than others; as a consequence these students would finish earlier, and their level of focus would decrease as they waited for other students. A possible limitation is that those students who have had previous gaming experience could have experienced further frustrations with VR technology, in relation to the quality of the graphics. This study did not track the prior gaming experience of individual respondents and this is something that should be addressed in future studies.
Open-ended feedback from teachers indicated both positive uses of this technology and limitations with their students. Overall, teachers reported a high level of engagement and indicated that students enjoyed making the GigaPan. Teachers liked that it was a change from traditional lecture styles and noted that variety is important to keep students engaged in the classroom. One teacher said that she liked how the videos and other materials in the GigaPan provided real visuals to support learning. Teachers described that when students made their own GigaPan it was more targeted to their actual activity and made the experience "come to life". Students were enthusiastic that they could access the virtual tour they made via a website to show to others. Teachers reported that they didn't like how some of the assets would freeze on the virtual tour if the internet connection wasn't strong enough and would have liked more of a follow up discussion with students after using the technology. One teacher also reported that although her students were more engaged they got distracted by the end of the session. Teachers responded that the main barrier to using this technology in future classrooms would be access to equipment but all reported that they would like to continue using the VR technology.

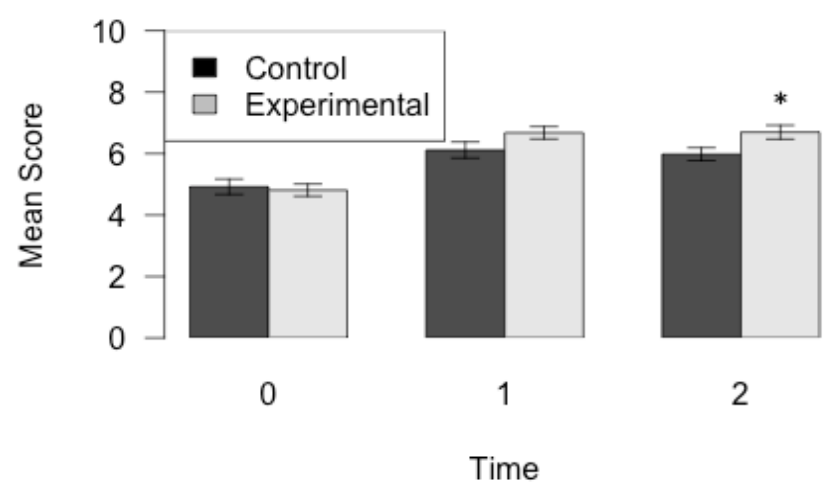

Figure 6. Mean score of knowledge questions $( \pm \mathrm{SE})$ out of 10 for each of the treatment groups at the three different time points. 


\section{DISCUSSION}

This study explored whether the use of VR to teach rocky intertidal ecology would enhance knowledge gain and retention. Our results showed that experimental and control groups had the same initial level of background knowledge, and that both traditional and VR-lesson plans led to similar knowledge gains. However, the knowledge gained was further maintained (short termed retained) with the use of GigaPan (VR) technology, as participants in the experimental group had a significantly higher score at the conclusion of the study $\left(\mathrm{t}_{2}\right)$. This observed difference could have resulted from either the initial exposure to the VR lesson plan, but also could have been attributed to the co-creation by students of their own virtual tours. Other studies have similarly found significantly higher learning scores with the use of virtual reality technology (De Freitas, 2006), and have emphasized the importance of hands-on learning in the classroom. In traditional lectures, students are passive learners and teachers tend to focus more on memorization of concepts. It can be harder for students to retain and apply knowledge in this type of environment where they are not as engaged. In contrast, hands on-learning such as VR technology can induce critical thinking and encourage students to ask questions (De Freitas, 2006). Observations also suggest the potentially important role of students feeling a sense of ownership and engagement in their final presentations. While this study did not explicitly separate the influence of VR, per se, and that of co-creating final presentations, our preliminary results suggest that further exploration into the use of student-created VR environments is warranted.

We also compared two different teaching methods for interest levels in students. There were no significant differences in engagement in science activities and excitement levels towards intertidal ecology among treatment groups at to, indicating the two groups started with an equal mix of students. Neither the control nor the experimental groups showed any increase in excitement $\left(\mathrm{t}_{1}\right)$ following participation in either type of lesson. This reflects a continued need to improve and evolve the VR technology for students. For example, it would be beneficial to use this technology with traditional methods that involve more direct contact with a teacher (Wrzeisin et al., 2010). Teachers whose students participated in this study reported that they would like more of a combination between the two lesson plans that would include a follow up discussion. Students also reported that they enjoyed the control lesson plan more than the GigaPan lesson plan at the end of the experiment $\left(\mathrm{t}_{2}\right)$. It is unclear why this result was reported but it may reflect some of the frustrations experienced by students based on problems with internet streaming due to low bandwidth and slow load times, and due to the need to wait for students who worked more slowly. Overall, students seemed to be more excited about the field trip, so differences between treatment groups had a lesser effect than the overall gain. Based on feedback from the teachers, students did seem to enjoy the VR lesson plan because it was a change from the traditional lecture style presentation.

Further Applications with "Flip Learning." In order to conduct survey assessments, we used Gigapan technology during in-class sessions. However, an additional application of this technology is through "flip learning" whereby students would access web-based virtual tours in their own homes. Offering students the opportunity to use virtual tours at home allows teachers to review the concepts students learned and have follow-up discussions during a subsequent in-class session. It is possible that when students use this technology on their own time, their enjoyment would potentially be greater because those that finished earlier would not have to wait until the rest of the class is done before moving on to other assignments. This would improve attention and enjoyment for the students that finished earlier than others during this study. It is important to note the advantages of the flipped learning aspect because students can access the materials on their own time at home which will also maximize classroom time for more engaging activities such as discussions, group work and field trips.

Teacher feedback. Overall feedback about GigaPan technology from the open-ended survey was very positive. One teacher said, "I really liked the use of the technology and the student-directed learning platform. Students were engaged the entire class, they appeared genuinely interested in the material that they were reading/learning about, and had better recall when I questioned them about the topic after the fact." Another teacher said, "I think it is a great interactive tool for the students to use when they can work at the own pace and focus on the things that are of most interest to them. It is interactive and allows them to use technology, which is always a hit. It is also available to them outside of the classroom so they can use it whenever they would like". Overall, all teachers reported that their students were much more engaged and it generated greater discussion between students. All teachers also reported that would like to continue using this technology, as it provides a way to bridge the gap between a student's experience during the field trip and science they needed to learn. One teacher stated, "It promoted inquiry, provided real visuals to support the learning, gave them the opportunity to discover and ask questions of themselves and the teacher, and lastly, supported the activity on the field trip. I think this was a superb way to get students involved 
and engaged." It can also support underserved learners that have trouble focusing in traditional learning settings. Based on feedback and the results of this study, this type of technology should be incorporated and further explored in the classroom.

Limitations and Future Studies. This study had certain limitations that should be addressed in future studies. All students were already enrolled in a marine science class, so interest and excitement levels were already very high, which left little room for improvement. In future studies, a focus on a wider variety of students could determine how interest levels shift for those students who aren't already actively signing up for marine science classes. This study only examined relatively short-term retention; future studies testing long-term retention to see how much participants remembered months after the exercise would be informative. This study also only measured factual knowledge, not procedural knowledge, during the field trip where they used a variety of tools to take measurements in the rocky intertidal habitat. Observations during the class sessions suggest improvement for the design of the virtual GigaPan lesson plan as well. For example, tracking might help determine if each student opened the PDF files and if they read it thoroughly or if instead they just skimmed the materials (Moreno-Ger et al., 2008). This could involve a more interactive game format and check list to make sure students are actively reading the slides. In addition, virtual reality is still an emerging technology. The ability to create and view VR is restricted to the availability of computers, Internet, mobile devices or VR goggles. These can be luxury items for poorly-funded communities and schools, where enhanced knowledge for children might be needed the most. New developments such as Google Cardboard VR have made this technology cheaper, but it is still unclear if VR technology can become affordable across all socio-economic communities.

Virtual tours in this study were used to prepare and reflect on field trips to the marine environment; however, future studies could expand on the effectiveness of this technology for those that don't have access to marine environments. This includes students living in landlocked areas and schools that don't have the resources for field trips to a marine environment., or for mobility-impaired students for whom access to the rocky shore may be difficult (Gilley et al., 2015). VR, while still somewhat costly may provide a cheaper alternative to studying marine environments that lower income schools can use. In accord with Spicer and Stratford (2001), a virtual field trip should not replace a real field trip, but it can be a very effective tool in preparing for it or in reviewing it. However, a virtual field trip would be better than not experiencing these environments at all. SVWs can also allow viewers to experience and learn about ecosystems from dis- tant sites, e.g. overseas, to which they otherwise do not have access. For example, students may also use virtual tours to describe local habitats and field experiences to overseas peers as part of international collaborative projects. Students may thus be able to transcend geographical boundaries and experience areas around the world virtually regardless of where they live (Bailenson, 2014). VR projects can also increase a student's "sense of place" (Vipin and Deepak, 2010) or connection with their own local environment, which can be shared with others to help understand similarities and differences to other environments.

It is important to study the efficacy of virtual reality environments in the classroom because these environments are a way to successfully illustrate anthropogenic impacts on marine ecosystems and what these environments could look like for future generations. Various studies have examined illustrating future climate change scenarios through the use of VR technology (Bailenson et al., 2014). It is often difficult to get someone to care about issues associated with climate change such as sea level rise if they have never even seen the ocean before. VR environments can help people visualize changes to marine environments and increase concern for the general public and stakeholders for how we are impacting the environment. This technology can also provide first-hand experiences to ecosystems that are degraded, allowing viewers to be immersed in various environments. In one study, viewers were able to dive in a degraded coral reef habitat and visualizations explained how human actions are causing problems for these environments. Those who read about the problem changed their behavior less than those who experienced it virtually (Ahn et al., 2016). Most conservation biologists believe that exposure to information alone is not enough to facilitate learning or encourage changes in behavior (Schultz, 2011). However, when a person is exposed to an environment through a personal experience such as virtual reality technology they are more likely to change their behavior (Bailenson, 2014). Interactive VR experiences can be cognitively and emotionally arousing which can create empathy to environmental problems (Ahn et al., 2016). This study revealed that current VR technology enhances learning of fundamental intertidal ecology. Future studies are needed to examine how this technology can go beyond fundamental learning and be used to illustrate environmental problems for the next generation of marine scientists.

\section{CONCLUSION}

This study highlights the importance of bringing technological advances into the classroom, and some of the challenges inherent in doing so. From the biographical questions the most common science activity was watching TV or an 
online video (Figure 5). This highlights how important technology is for younger generations for accessing scientific information. Past studies have shown that VR technology can help immerse students in nature and bring about a connection through a technological approach. This study instead showcases how VR technology can be more beneficial for studying ecological concepts, in terms of short-term knowledge retention, when compared to traditional methods. This short-term knowledge retention can ultimately result in the hands-on nature of the Gigapan technology, which further supports that interactive education can provide greater positive effect for students in both traditional or VR lessons. Nevertheless, experiments like this can influence teachers to use more technology-based methods for learning in their own classrooms (Mayer, 2014). More studies are needed for further feedback from teachers and students so appeal and excitement may also be enhanced. However, the success of this technology in the classroom for learning different ecological concepts about the rocky intertidal environment reveals that GigaPan technology provides a way to bring new, innovative technologies into the classroom to increase student's ability to retain knowledge.

\section{ASSOCIATED CONTENT}

Appendices mentioned in this manuscript can be found uploaded to the same webpage as this manuscript.

\section{AUTHOR INFORMATION Corresponding Author}

Emily Duwan. Marine Science Center. Northeastern University. 430 Nahant Road, Nahant, MA 01908. e.duwan@ northeastern.edu

\section{Author Contributions}

The manuscript was written through contributions of all authors. All authors have given approval to the final version of the manuscript.

\section{FUNDING SOURCES}

This project was supported by the Three Seas Program, NASA grant NNX11AP77G, and NSF grant OCE-1635989 to $\mathrm{BH}$. This is publication number 392 of the Northeastern University Marine Science Center.

\section{ACKNOWLEDGEMENTS}

We would like to thank all of the students and teachers that participated in this study. Many thanks to Dr. Steven Scyphers for assistance with data analysis, and Valerie Perini and the rest of the Outreach Staff at the Marine Science Center for help with field trips. We would also thank the Three Seas Program for funding for the project, which comprised the MS thesis of ED.

\section{REFERENCES}

Ahn, S.J., Bostick, J., Ogle, E., Nowak, K., McGillicuddy, K.T., and Bailenson, J.N. (2016). Experiencing nature: Embodying animals in immersive virtual environments increases inclusion of nature in self and involvement with nature. Computer-Mediated Communication, 21, 399-419.

Gilley, B., Atchinson, C., Feig, A., and Stokes, A. (2015). Impact of inclusive field trips. Nature Geoscience, 8, 579-580.

Bailenson, J. (2014). Virtual reality could make a real difference in environment. SF Gate, 1-6.

Bhagat, K.K., Liou, W.K., and Chang, C.Y. (2016). A cost-effective interactive $3 \mathrm{D}$ virtual reality system applied to military live firing training. Virtual Reality, 20, 127-140.

Boada, I., Rodriguez-Benitez, A., Garca-Gonzalez, J.M., Olivet, Josep., Carreras, V., and Sbert, M. (2015). Using a serious game to complement CPR instruction in a nurse faculty. Computer Methods and Programs in Biomedicine, 122, 282-291.

De Freitas, S. (2006). Learning in immersive worlds: A review of game-based learning. JISC e-Learning Programme, 1-72.

De Freitas, S., and Neumann, T. (2009). The use of 'exploratory learning' for supporting immersive learning in virtual environments. Computers and Education, 52, 343-352.

De Freitas, S., and Oliver, M. (2006). How can exploratory learning with games and simulations within the curriculum be most effectively evaluated? Computers and Education, 46, 249-264.

Guillen-Nieto, V., and Aleson-Carbonell, M. (2011). Serious games and learning effectiveness: The case of It's a Deal. Computers and Education, 58, 435-448.

Hussain, S., Ahmad, N., Saeed, S., and Khan, F. N. E. (2015). Effects of flip learning approach on prospective teachers' pedagogical skills. The Dialogue, 10 (3).

Liou, W.K., Bhagat, K.K., and Chang, C.Y. (2016). Beyond the flipped classroom: A highly interactive cloud-classroom (HIC) embedded into basic materials science courses. Journal of Science Education Technology, 25, 460-473.

Moreno-Ger, P., Burgos, D., Martinex-Ortiz, I., Sierra, J.L., and Fernandez-Manjon, B. (2008). Educational game design for online education. Computers in Human Behavior, 24, 2530-2540.

Paine, R. T. (1994). Marine rocky shores and community ecology: An experimentalist's perspective. Ecology Institute, Oldendorf/Luhe, Germany. Journal of the Marine Biological Association of the United Kingdom, 75 (1), 262. 
Papastergiou, M. (2009). Digital game-based learning in high school computer science education: Impact on educational effectiveness and student motivation. Computers and Technology, 52, 1-12.

Schultz, P.W. (2011). Conservation means behavior. Conservation Biology, 25 (6), 1080-1083.

Sianez, D.M., Fugere, M. A., and Lennon, C.A. (2010). Technology and engineering education students' perceptions on hands-on and hands-off activities. Research in Science and Technological Education, 28 (3), 291-299.

Spicer, J.I. and Stratford, J. (2001). Student perceptions of a virtual field trip to replace a real field trip. Journal of Computer Assisted Learning, 17 (4), 345-354.

Thorner, J., Kumar, L., and Smith, S. (2014). Climate-change-driven sea level rise on intertidal rocky reef habitats will be variable and site specific. PLOS, 9 (1), 1-7.

Tsiatsos, T., Andreas, K., and Pomportis, A. (2010). Evaluation framework for collaborative educational virtual environments. Educational Technology and Society, 13 (2), 65-77.

Wrzesien, M., and Raya, M. (2010). Learning in serious virtual worlds: Evaluation of learning effectiveness and appeal to students in the E-Junior Project. Computers and Education, $55,178-287$.

Wrzesien, M., Lopez, D.P., and Raya, M.A. (2010). Learning ecology issues of the Mediterranean Sea in a virtual aquatic world pilot study. Journal of CyberTherapy and Rehabilitation, 3, 255-260.

Vipin, A., and Deepak, K. (2010). Sense of place in virtual world learning environments: A conceptual exploration. Information Systems and Quantitative Analysis Faculty Proceedings and Presentations, 8.

Yahaya, R. A. (2006). Assessing the effectiveness of virtual reality technology as part of an authentic learning environment. Proceedings of the Sixth International Conference on Advanced Learning Technologies, 6, 1-3. 